\title{
IDENTIFIKASI UMAH ADAT PITU RUANG SEBAGAI PRODUK KEBUDAYAAN GAYO. STUDI KASUS: UMAH REJE BALUNTARA DI ACEH TENGAH
}

\author{
Fani Dila Sari ${ }^{1^{*}}$, Haria Nanda Pratama ${ }^{2 *}$, Indra Setiawan ${ }^{3^{*}}$ \\ Jurusan Seni Pertunjukan ${ }^{1}$ dan 2 , Jurusan Seni Rupa dan Desain ${ }^{3}$ \\ Institut Seni Budaya Indonesia (ISBI) Aceh \\ Jl. Transmigrasi, Gampong Bukit Meusara, Kec. Kota Jantho,Kab. Aceh Besar, Kode Pos 23911 \\ Aceh. Indonesia \\ Email:fanidilasari@isbiaceh.ac.id, hariananadapratama@isbiaceh.id,indrasetiawan@isbiaceh.id
}

\begin{abstract}
Abstrak
Umah Adat Pitu Ruang merupakan karya seni bangunan rumah adat Suku Gayo. Struktur bangunannya berupa rumah panggung yang memiliki 36 tiang sebagai penopang dengan ornamen-ornamen berbagai warna yang menghiasi Umah Adat Pitu Ruang. Rumah adat Gayo ini memiliki fungsi tidak hanya sebagai bangunan tempat tinggal, namun sebagai identitas budaya Gayo sekaligus penerapan nilai-nilai estetis bagi masyarakatnya. Identifikasi Umah Adat Pitu Ruang sebagai produk kebudayaan Gayo dibentuk oleh tatanan hidup masyarakatnya. Salah satu hasil kebudayaan yang masih ada di daerah Takegon Aceh Tengah yaitu Umah Adat Pitu Ruang. Kebudayaan ini diwariskan oleh leluhur suku Gayo yang representasi wujud kehidupan sosial budaya masyarakat Takegon Aceh Tengah. Rumah adat ini merupakan peninggalan bersejarah atau sebuah mahakarya seni yang memiliki filosofi kehidupan yang berlandaskan kepada nilai-nilai sosial masyarakatnya dilihat dari bangunannya. Studi kasus: Umah reje Baluntara di Aceh Tengah dengan metode penelitian kualitatif.
\end{abstract}

Kata Kunci: gayo, kebudayaan, umah, pitu, ruang.

\begin{abstract}
The Umah Adat Pitu Ruang is a work of art for the traditional house of the Gayo tribe. The structure of the building is in the form of a house on stilts which has 36 pillars as a support with various colored ornaments that adorn the Umah Adat Pitu Ruang. This Gayo traditional house has a function not only as a residential building, but as a Gayo cultural identity as well as the application of aesthetic values to the community. The identification of the Pitu Ruang Adat Umah as a product of Gayo culture is shaped by the life order of the people. One of the cultural products that still exist in the Takegon area of Central Aceh is the Pitu Room Umah Adat Pitu Ruang. This culture was inherited by the ancestors of the Gayo tribe who represented the socio-cultural life of the Takegon people of Central Aceh. This traditional house is a historical heritage or a masterpiece of art which has a philosophy of life based on the social values of the community as seen from the building. Case study: Umah reje Baluntara in Central Aceh using qualitative research methods.
\end{abstract}

Keywords: gayo, cultural, umah, pitu, ruang.

\section{PENDAHULUAN}

Setiap daerah yang ada di Indonesia mempunya sistem adat, begitu juga dengan suku Gayo yang mendiami wilayah dataran tinggi, mempunyai adat sesuai dengan kepercayaan yang dianutnya. Ajaran agama Islam telah mempengaruhi masyarakat di suku gayo dimulai pada abat ke 8 masehi yang sebelumnya menganut kepercayaan animisme. Pengaruh ini tumbuh dan berkembang sehingga mempengaruhi sistem berfikir masyarakat gayo sehingga hal ini berdapak kepada cara menjalankan segala bentuk aktifitas kehidupan masyarakatnya. Menurut Ibrahim (2007: 5) lebih kurang pada tahun 1115 Masehi, Raja (reje) Islam kerajaan Lingga yang oleh penduduk Negeri Lingga (negeri Linge) disebut "Petu Merhum Mahkota Alam" untuk pertama kalinya merumuskan norma adat bersama para ulama dan pemimpin masyarakat lainnya yang disusun di Istana Raja Lingge (Reje Lingge) Umah Adat Pitu Ruang negeri Lingge oleh raja Petu Mehrum mahkota Alam.

Umah Adat Pitu Ruang merupakan sebuah karya seni kolektif rumah adat karya budaya Suku Gayo, secara struktur bangunan Rumah adat gayo merupakan rumah panggung yang memiliki 36 tiang sebagai penopang bangunan, memiliki tangga masuk berada di luar rumah, pintu rumahnya tingginya sekitar $1.50 \mathrm{~m}$. dan juga terdapat penempatan garapan ornament-ornamen yang mengisi struktur serta pemakaian warna di rumah Umah Adat Pitu Ruang. Selain itu rumah adat gayo ini 
memiliki fungsi tidak hanya sebagai bangunan yang dijadikan tempat tinggal, akan tetapi di dalam penciptaannya merupakan sebuah produk kebudayaan.

\section{KAJIAN TEORI}

Kebudayaan menjadi dasar dalam memahami hasil karya manusia yang tertuang dalam berbagai unsur dan salah satu nya adalah bukti peningalan sejarah. Unsurunsur kebudayaan itu sendiri secara universal terbagi dalam tujuh unsur yaitu; sistem agama dan upacara keagamaan, sistem organisasi masyarakat, sistem pengetahuan, bahasa, kesenian, sistem mata pencarian hidup, dan sistem teknologi, (Koentjaraningrat. 2004). Keseluruhan unsur ini kemudian menjadi landasan dalam kehidupan masyarakat untuk dijalani dalam berbagai aspek kehidupan, dengan berbagai bentuk aktivitas dalam kehidupan social masyarkat. Kebudayaan ini juga berfungsi dalam menentukan norma, perilaku yang teratur serta meneruskan adat dan nilai-nilai kebudayaan, sesuai dengan kebutuhan dari masyarakatnya.

Hal ini akan menyebabkan terjadinya perbedaan dalam pelaksanaan dari aktivitas yang dilakukan dan menyebabkan setiap kelompok masyarakat akan melahirkan kebudayaan dan adat-istiadat yang berbeda-beda. Memiliki peninggalan warisan budaya yang berbeda dan pola hidup dan tingkah laku yang beragam menjadikan struktur pola pikir masyarakat yang plural, baik mitos maupun sistem nilai dari setiap masyarakatnya dalam menghasilkan suatu unsur kebudayaan yang tidak sama. Sehingga dapat mempererat ikatan solidaritas, dan menjadi ciri dan pembeda dari masing-masing kelompok masyarakat.

Umah Adat Pitu Ruang merupakan artefak budaya yang telah diciptakan oleh nenek monyang suku Gayo, setiap karya seni budaya memiliki beberapa aspek utama seperti yang disampaikan I Made Bandem dalam Ferawati (2010: 84) meyatakan bahwa "ditinjau dari segi wujud, kebudayaan memiliki tiga aspek utama, yaitu: Ide (gagasan), Wujud (bentuk) dan prilakunya". Setiap karya seni budaya pasti memiliki unsur-unsur tersebut sama halnya dengan rumah adat Gayo, hasil dari produk budaya yang berangkat dari ide, yang kemudian di wujud kan kedalam bentuk rumah adat.

\section{METODE PENELITIAN}

Metode dalam penelitian ini adalah penelitian kualitatif. Pemilihan metode ini karena peneliti akan melakukan pengumpulan data terhadap subjek maupun objek dalam penelitian ini. Creswell (2010:261) bahwa dalam penelitian kualitatif peneliti adalah instrument
Gorga : Jurnal Seni Rupa

Volume 09 Nomor 02 Juli-Desember 2020 p-ISSN: 2301-5942 | e-ISSN: 2580-2380

kunci (Researcher as Key Instrument) yang mengumpulkan sendiri data melalui dokumentasi, observasi dan wawancara dengan partisipan. Hal ini menunjukan bahwa metode ini digunakan sebagai jalan dalam mewujudkan luaran penelitian. Hasil dari analisis data yang dilakukauan oleh peneliti dideskripsikan menjadi sebuah laporan hasil penelitian yang kemudian diwujudkan menjadi luaran penelitian dalam bentuk artikel ilmiah.

Pendekatan yang dilakukan oleh peneliti adalah emik dengan melakukan studi pustaka dan teknik wawancara dengan narasumber yang memiliki pengetahuan terkait objek material. Pendekatan emik menganalisa perilaku atau gejala sosial dari pandangan masyarakatnya sendiri dan budayawannya. Moleong (2006:3) mengatakan bahwa "penelitian kualitatif merupakan prosedur penelitian yang menghasilkan data kualitatif berupa kata-kata tertulis maupun lisan dari perilaku orang-orang yang diamati”. Berdasarkan hal tersebut, maka metode kualitatif dijadikan sebagai alur pelaksanaan penelitian.

\section{HASIL DAN PEMBAHASAN}

\section{Hasil}

Di dataran Gayo terdapat empat kerajaan yang masingmasingnya memiliki rumah adat sendiri. Namun, pada saat ini rumah adat yang masih asli hanya tinggal satu yaitu rumah adat kerajaan Baluntara. Rumah adat kerajaan Baluntara adalah sebuah peninggalan budaya tertua pada saat ini, kurang lebih sudah berumur 200 tahun. Rumah adat Gayo kerajaan Baluntara terletak di pinggir Danau Luat Tawar kampung Toweren Kecamatan Laut Tawar. Komponen rumah adat ini masih asli, begitu juga dengan ukirannya masih asli belum ada perubahan.

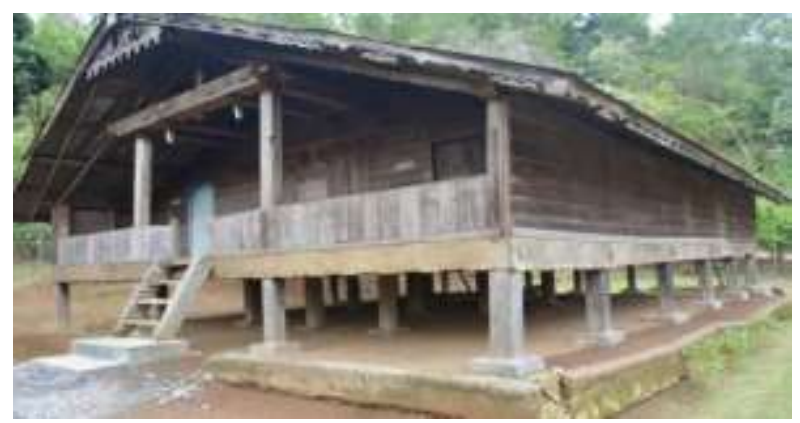

Gambar 1. Tampak Kiri Rumah Adat Gayo Kerajaan Baluntara (Pratama, 2019)

Dahulunya rumah adat ini ditempati oleh para reje (raja). Sebagai istana kerajaan, rumah adat ini dulunya difungsikan untuk tempat bermusyawarah dalam mengatur pelaksanaan acara adat di suku Gayo. Umah Adat Pitu Ruang (rumah adat tujuh ruang) merupakan 


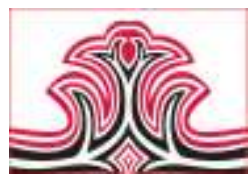

rumah adat yang dibangun berdasarkan edet urum ukum (hukum dan adat). Edet ditetapkan melalui Sarak opat (musyawarah) yaitu sebuah hukum yang berlandaskan kepada agama (wawancara Hajar: 10 Juli 2020).

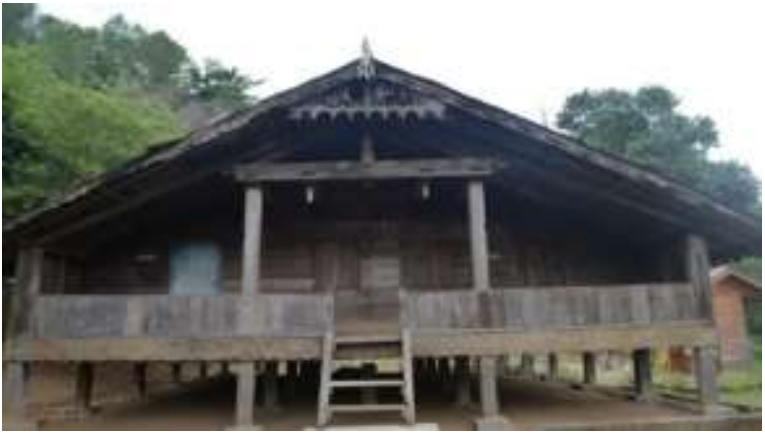

Gambar 2. Tampak Depan Rumah Adat Gayo Kerajaan Baluntara (Pratama, (2019).

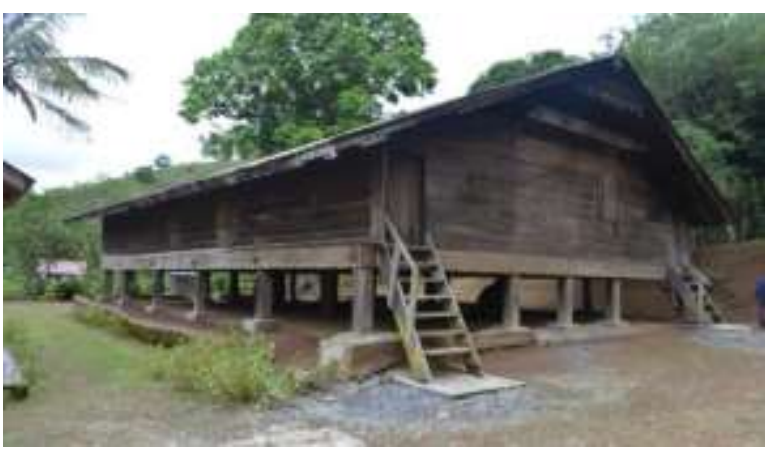

Gambar 3. Tampak Belakang Rumah Adat Gayo Kerajaan Baluntara (Pratama, 2019)

\section{Pembahasan}

Umah Reje Beluntara merupakan rumah tempat tingga raja beserta aktifitasya. Sebagai rumah dari seorang raja yang menguasai daerah Toweren sebagai muara dari segala macam bentuk penghadiran dan penataan untuk mengatur laju kehidupan masyarakatnya, secara struktur kepemimpinan yang menempati rumah ini dari generasi kegenerasi dapat diterangkan dengan tabel berikut:

Tabel 1. Generasi Raja Baluntara

\begin{tabular}{|c|c|c|}
\hline No. & $\begin{array}{c}\text { Raja yang mendiami Umah } \\
\text { Reje Beluntara Toweren } \\
(1860)\end{array}$ & $\begin{array}{c}\text { Tahun } \\
\text { Berkuasa }\end{array}$ \\
\hline 1 & Raja Pertama R. Djeludin & $1850-1895$ \\
\hline 2 & Raja Kedua R. Selamat & $1896-1926$ \\
\hline 3 & Raja Ketiga R. Sareh & $1927-1945$ \\
\hline
\end{tabular}

Untuk Raja ke empat yang masih hidup sampai saat ini dan menjadi salah satu acuan sumber pada penelitian ini memaparkan bahwa pengakuan sebagai raja dari
Gorga : Jurnal Seni Rupa

Volume 09 Nomor 02 Juli-Desember 2020 p-ISSN: 2301-5942 | e-ISSN: 2580-2380

kerajaan Beluntara ini telah dihapuskan semenjak kemerdekaan Negara republik indonesia tahun 1945. Akan tetapi untuk hak milik dari rumah adat ini masi dipegang oleh garis keturunan raja dari kerajaan baluntara sampai saat ini.

Umah pitu ruang mengandung unsur nomorik angka pitu atau tujuh. Tentunya angka tujuh ini memiliki dasar filosofi yang kaitannya berhubungan dengan adat Gayo. Bagi masyarakat Gayo angka pitu ini mempunyai nilai sakral mengandung filosofi dalam kehidupan manusia. Menurut Joni (dalam jurnal Ansar Salihin, dkk, 2019: 72) Filosofi angka tujuh dalam masyarakat Gayo "kulangit bintang pitu, kubumi kal pitu kala" Induk dari ku langit bintang pitu (ke langit bintang tujuh) adalah tujuh anggota tubuh dalam menghadap tuhan dan induk ku bumi kal pitu mata (ke bumi kal/takaran tujuh mata) adalah enam rukun iman ditambah satu adat. Gabungan keduanya menjadi tujuh dasar mengatur kehidupan manusia yaitu ayat, sabda, kiyes (kiyas), ijma', inget (Ingat), resam, atur (aturan). Filosofi inilah yang diterapkan dalam rumah adat Gayo umah pitu ruang.

Angka pitu atau tujuh menurut pandangan masyarakat Gayo. Filosofi tujuh anggota tubuh dalam ibadah kepada Allah diperkuat dengan mempercayai rukun iman. Filosofi itu juga diterapkan dalam rumah adat Gayo tujuh komponen yang kontruksikan pada bagian atas rumah adat Gayo agar kokoh pada bagian atap dan tujuh komponen dikontruksikan pada bagian bawah agar kokoh dibagian lantai rumah adat Gayo. Melalui filosofi itu juga rumah adat Gayo dibuat tujuh ruang dan disebut juga namanya Umah Adat Pitu Ruang.

Bentuk merupakan sesuatu yang tampak, kongkrit dapat dilihat dengan menggunakan panca indra. Rumah adat sebagai seni arsitektur merupakan salah satu wujud pelahiran nilai estetika bagi masyarakat suku Gayo kedalam bentuk karya seni. Keberadaanya sebagai salah satu kekayaan budaya tradisional yang terus dipertahankan oleh masyarakat Gayo dalam upaya pelestarianya. Dikarenakan sebuah produk budaya merupakan manifestasi pemikiran dan pandangan hidup masyarakat yang dilahirkan oleh leluhur masyarakat suku Gayo dalam bentuk rumah adat Gayo. Setiap daerah memiliki bentuk dan cirikhas rumah tersendiri sesuai dengan iklim dan geografis wilayahnya.

Umah Adat Pitu Ruang merupakan artefak budaya yang telah diciptakan oleh nenek monyang suku Gayo, setiap karya seni budaya memiliki beberapa aspek utama seperti yang disampaikan I Made Bandem dalam Tesis Ferawati (2010:84) meyatakan bahwa "ditinjau 
dari segi wujud, kebudayaan memiliki tiga aspek utama, yaitu: Ide (gagasan), Wujud (bentuk) dan prilakunya". Setiap karya seni budaya pasti memiliki unsur-unsur tersebut sama halnya dengan rumah adat Gayo, hasil dari prodak budaya yang berangkat dari ide, yang kemudian di wujud kan kedalam bentuk rumah adat serta tidak terlepas juga dari nilai filosofis dan estetika.

Rumah adat Gayo memiliki bentuk yang hampir sama dengan rumah adat daerah Aceh lainya. Bentuk rumah adatnya rumah panggung, rumah adat Gayo memiliki peranan yang sangat penting bagi kehidupan masyarakat suku Gayo, karena difungsikan sebagai kegiatan yang berhubungan dengan adat dilakukan di atas rumah ini. Umah Adat Pitu Ruang Gayo pada terbuat dari bahan material kayu, yang kemudian diberi ukiran pada material kayunya, baik pada tangga, dinding, tiang, pintu dan yang paling menonjol adalah pada pepir/tolak angina. Rumah adat Gayo terbuat dari kayu Simantuk atau Damar Laut. Kayu ini berserat padat dan keras, sehingga tidak mudah dimakan serangga dan rayap menjadikan rumah adat lebih awet. Pemilihan kayu juga melalui berbagi ritual pada masa raja.

Rumah adat Tujuh Ruang memiliki ukuran umum panjang 9 meter dan lebar 12 meter. Dengan bentuk rumah, seperti rumah panggung pada umumnya dengan 5 anak tangga, menghadap utara. Didalamnya terdapat 4 buah kamar, dan 2 ruang bebas (lepo) di timur \& barat. Bentuk bagian dari rumah adat Gayo terdiri dari, Tulak Angina, Pepir, Bere, Ruk, Suyen, dan Kite sebagai berikut: 1). Tulak Angina, 2). Pepir, 3). Bere, 4). Ruk, 5). Suyen, dan 6). Kite.

Rumah adat Gayo ini memiliki bagian-bagian ruangan, setiap ruang memiliki fungsi masing-masing.

Kamar 1: petue (orang tua)

Kamar 2 : reje (raja) ditadai dengan tiang besar yang terdapat di dalam kamar.

Kamar 3 dan 4 : untuk anggota keluarga raja.

Lepo kanan : : untuk berkumpulnya para laki-laki dalam acara adat.

Lepo kiri :untuk berkumpulnya para perempuan dalam acara adat.

Dapur : : tempat berkumpul para perempuan.

\section{KESIMPULAN DAN SARAN}

\section{Kesimpulan}

Kehidupan sosial masyarakat Gayo berpedoman kepada hukum dan adat istiadat yang dibuat oleh masyarakatnya. Salah satu hasil kebudayaan yang masih ada di daerah Takegon Aceh Tengah yaitu Umah
Adat Pitu Ruang. Kebudayaan ini diwariskan oleh leluhur suku Gayo yang menvisualkan wujud representasi kehidupan sosial budaya masyarakat Takegon Aceh Tengah. Rumah adat ini merupakan peninggalan bersejarah atau sebuah mahakarya seni yang memiliki filosofi kehidupan yang berlandaskan kepada nilai-nilai Islam dilihat dari bentuk dan strukturnya.

\section{Saran}

Ada beberapa saran yang dapat dijadikan bahan masukan yaitu : 1). Perhatian dan pengenalan pada Umah Adat Pitu Ruang sebagai produk kebudyaaan lokal Aceh lebih ditingkatkan lagi 2). Dibutuhkan analisis dan penelitian lebih lanjut terkait konsep kebudayaan Gayo yang dapat ditinjau dari bangun Umah Adat Pitu Ruang.

\section{DAFTAR RUJUKAN}

Ferawati, (2010). Motif Kerawang Gayo Busana Adat Pengantin Gayo Aceh Tengah. Tesis tidak diterbitkan. Padapanjang: Program Pasca Sarjana ISI Padangpanjang.

Hajar, Ibnu. (2020). "Wawancara Penelitian tentang Umah Adat Pitu Ruang". Hasil Wawancara Pribadi: 10 Juli 2020, Desa Lut Tawar Kabupaten Aceh Tengah.

Ibrahim, Mahmud. (2007). Mujahid Dataran Tinggi Gayo. Tekengon: Yayasan Maqmam Mahmuda Takengon.

Koentjaraningrat. (2004). Kebudayaan Mentalitas dan Pembangunan. Jakarta: PT. Gramedia.

Moleong, Lexy. J. (2002). Metode Penelitian Kualitatif. Bandung: PT. Remaja Rosdakarya.

Pratama, H. N. (2019) "Foto Kegiatan Penelitian tentang Rumah Adat Gayo Kerajaan Baluntara". Hasil Dokumentasi Pribadi: 20 September 2020, Desa Lut Tawar Kabupaten Aceh Tengah. 